\title{
MORFOLOGIA DE DIÁSPOROS E PLÂNTULAS DE ESPÉCIES ARBÓREAS DA FLORESTA COM ARAUCÁRIA, NO SUL DO BRASIL
}

\author{
Alessandra Mara Gogosz ${ }^{1 *}$, Maria Regina Torres Boeger ${ }^{2}$, Nelson Luiz Cosmo ${ }^{3}$, \\ Antônio Carlos Nogueira ${ }^{4}$ \\ ${ }^{1 *}$ Universidade Federal do Paraná, Programa de Pós Graduação em Ecologia e Conservação, Curitiba, PR, Brasil - \\ alegogosz@gmail.com.br \\ ${ }^{2}$ Universidade Federal do Paraná, Departamento de Botânica, Curitiba, Paraná, Brasil - mrtboeger@ gmail.com.br \\ ${ }^{3}$ Universidade Federal do Paraná, Programa de Pós Graduação em Engenharia Florestal, Curitiba, Paraná, Brasil - \\ ncosmo@gmail.com \\ ${ }^{4}$ Universidade Federal do Paraná, Departamento de Ciências Florestais, Curitiba, Paraná, Brasil - nogueira @ ufpr.br
}

Recebido para publicação: 15/01/2014 - Aceito para publicação: 17/05/2015

\begin{abstract}
Resumo
Neste estudo foram caracterizados morfologicamente frutos, sementes e plântulas de espécies da Floresta com Araucária (Floresta Ombrófila Mista), visando entender as estratégias de estabelecimento de diferentes grupos ecológicos. Frutos de 18 espécies arbóreas foram coletados na região de Curitiba, Paraná. As sementes foram semeadas em vermiculita e mantidas em laboratório, até a fase de plântula. Nas espécies pioneiras predominam frutos secos, deiscentes, sementes exalbuminosas, pequenas, com estruturas que favorecem a dispersão anemocórica e plântulas com cotilédones finos, foliáceos com tricomas. Nas secundárias tardias os frutos são carnosos com dispersão zoocórica, as sementes são albuminosas e as plântulas possuem cotilédones crassos, foliáceos, e, em alguns casos, também com função de reserva. Nas secundárias iniciais, as características são variáveis. A caracterização morfológica realizada dá subsídio, no contexto da ecologia funcional, à interpretação das diferentes estratégias de estabelecimento das espécies.

Palavras-chave: Grupos ecológicos; estabelecimento; morfologia funcional; Floresta Ombrófila
\end{abstract} Mista.

\begin{abstract}
Morphology of diaspore and seedling of tree species of the Araucaria forest (Subtropical Ombrophilous Forest) in southern Brazil. This study characterized morphologically the fruits, seeds and seedlings of species of Araucaria Forest, aiming to understand the strategies of establishing different successional groups. Therefore, fruits of 18 tree species were collected in Curitiba, Paraná. Then the seeds were sown in vermiculite and remained in the laboratory until the seedling stage. The pioneer species have predominantly dehiscent dry fruits, unalbuminous seeds, small structures that favor anemochoric dispersal and seedlings with thin cotyledons, foliaceous with trichomes. In late secondary species the fruits are fleshy with zoochorous dispersal, seeds are albuminous and seedlings present fleshy cotyledons, foliaceous, and in some cases also reserve function. In the early secondary species, the characteristics are variable. Morphological characterization allows the interpretation of functional ecology, the different strategies of establishment of species.
\end{abstract}

Keywords: Succession groups; establishment; functional morphology; Mixed Ombrophilous Forest.

\section{INTRODUÇÃO}

O estabelecimento das plântulas é uma fase crítica para a sobrevivência das espécies arbóreas, uma vez que são mais vulneráveis às diversas variações ambientais neste estágio, em que a competição e a predação são intensas (LECK et al., 2008). Neste contexto, a probabilidade de uma plântula se estabelecer com sucesso, originando um indivíduo adulto, é geralmente pequena (KITAJIMA, 2007). Além disso, os aspectos relacionados às síndromes de dispersão e as características morfológicas das

FLORESTA, Curitiba, PR, v. 45, n. 4, p. 819 - 832, out. / dez. 2015.

Gogosz, A. M. et al.

ISSN eletrônico 1982-4688 / ISSN impresso 0015-3826

819

DOI: $10.5380 /$ rf.v45i4.35017 
sementes e dos frutos influenciam no estabelecimento e sobrevivência das plântulas (MOLES et al., 2005).

Em diversos estudos têm-se analisado os aspectos morfológicos e funcionais das sementes e das plântulas (GARWOOD, 1996; WRIGHT et al., 2000; IBARRA-MANRÍQUEZ et al., 2001; RESSEL et al., 2004; KITAJIMA; MYERS, 2008; MOLES; LEISHMAN, 2008, etc.). Porém, esses estudos são relativamente escassos, quando se trata de espécies da flora brasileira, especialmente da Floresta com Araucária (Floresta Ombrófila Mista).

Assim como ocorreu com a maior parte da vegetação do sul do Brasil, a Floresta com Araucária foi muito explorada, restando poucos remanescentes de floresta secundária, levando à redução significativa de sua biodiversidade. Dentre os estudos que contribuem para o conhecimento das plântulas dessa unidade fitogeográfica citam-se Kuniyoshi (1981); Cosmo et al. (2009, 2010); Gogosz, et al. (2010); Rego et al. (2011). No entanto, esses estudos têm enfoque mais morfológico e descritivo, havendo necessidade de estudos que abordem os aspectos ecológicos das plântulas.

O conhecimento da morfologia dos frutos, das sementes e das plântulas é essencial para compreender o ciclo de vida das espécies vegetais, para a identificação das espécies, assim como para auxiliar os estudos de regeneração de áreas naturais (KUNIYOSHI, 1981). As variações na morfologia e anatomia da semente, como a textura e cor do tegumento, organização do embrião e tipo de endosperma, bem como a forma e as dimensões da semente, podem estar relacionadas às estratégias de dispersão e de germinação das espécies vegetais (PAOLI, 2006). Moles et al. (2005) destacam que as dimensões das sementes influenciam no desenvolvimento das espécies, estando relacionadas às condições ambientais em que as plântulas se estabelecem.

Desse modo, considerando os aspectos morfológicos das sementes e das plântulas, as espécies podem ser classificadas em grupos ecológicos distintos, de acordo com a fase de estabelecimento (PIÑARODRIGUES et al., 1990; RESSEL et al., 2004).

Com base nesses pressupostos, foram estudados os diásporos e as plântulas de 18 espécies arbóreas, pertencentes a diferentes grupos ecológicos, quanto ao estágio sucessional, visando verificar se $i$ : as características morfológicas dos diásporos e das plântulas de grupos ecológicos distintos da Floresta com Araucária estão relacionadas às estratégias de estabelecimento das espécies; ii: tais caracteres permitem separar as espécies estudadas em diferentes grupos ecológicos.

\section{MATERIAL E MÉTODOS}

Frutos maduros de 18 espécies arbóreas (provenientes de sete ou mais matrizes), de grupos ecológicos distintos foram coletados entre 2009 e 2011, na região metropolitana de Curitiba, Paraná, em remanescentes da Floresta com Araucária (Tabela 1). Nessa região ocorre clima subtropical úmido mesotérmico ( $\mathrm{Cfb}$ de Koeppen), com verões frescos e invernos com geadas frequentes. A temperatura média anual é de $18{ }^{\circ} \mathrm{C}$, com alguns meses mais frios, com médias inferiores aos $15^{\circ} \mathrm{C}$ e a precipitação média anual varia de 1400 a 1600 mm (MAACK, 1981).

O material botânico herborizado foi tombado no Herbário da Faculdades Integradas "Espírita" (HFIE), registrado sob n ${ }^{\circ}$ 9500-9518.

A nomenclatura binomial utilizada está de acordo a Lista de espécies da Flora do Brasil (2014). Para a classificação das espécies em grupos ecológicos foram utilizados os parâmetros citados por PiñaRodrigues (1990).

Os frutos secos deiscentes foram mantidos em ambiente natural, até sua completa abertura. Posteriormente, as sementes foram retiradas manualmente. Dos frutos carnosos, as sementes foram extraídas e secas em laboratório durante 24 horas, em temperatura ambiente. Cinquenta unidades foram selecionadas aleatoriamente, de cinco a dez indivíduos por espécie, para observação e caracterização dos aspectos externos dos frutos e das sementes. A descrição e as ilustrações morfológicas foram realizadas a olho nu e com auxílio de microscópio estereoscópico, utilizando-se paquímetro digital para a obtenção das dimensões. Realizaram-se secções transversais e longitudinais das sementes, tendo sido analisadas as seguintes características: forma da semente, presença ou ausência de tecidos de reserva, consistência do tegumento, presença de excrescências (ala, arilo, opérculo, etc.) e forma do embrião. A descrição morfológica dos frutos e das sementes foi realizada com base nos estudos de Kuniyoshi (1981) e Barroso et al. (1999). Como apoio à caracterização morfológica das plântulas foi consultado os estudos de Souza (2003). 
Tabela 1. Espécies amostradas da Floresta com Araucária, no Sul do Brasil.

Table 1. Sampled species of Araucaria forest, in southern Brazil.

\begin{tabular}{lcc}
\hline Espécie (Família) & G.S. & Frutificação \\
\hline Clethra scabra Loisel. (Clethraceae) & pi & mar-abr \\
Moquiniastrum polymorphum (Less.) G. Sancho & pi & jan-fev \\
Lamanonia ternata Vell. (Cunoniaceae) & pi & jun-ago \\
Schinus terebinthifolius Raddi (Anacardiaceae) & pi & jan-mai \\
Luehea divaricata Mart. (Malvaceae) & pi & mai-jul \\
Casearia sylvestris Sw. (Salicaceae) & si & set-dez \\
Cedrela fissilis Vell. (Meliaceae) & si & jul-ago \\
Lafoensia pacari A.St.-Hil. (Lythraceae) & si & abr-out \\
Psidium cattleianum Sabine (Myrtaceae) & si & mar-abr \\
Gymnanthes klotzschiana Müll.Arg. (Euphorbiaceae) & si & dez-jan \\
Handroanthus albus (Cham.) Mattos (Bignoniaceae) & si & out-nov \\
Allophylus edulis Niederl. (Sapindaceae) & st & nov-dez \\
Ilex paraguariensis A.St.-Hil. (Aquifoliaceae) & st & jan-abr \\
Mollinedia clavigera Tul. (Monimiaceae) & st & mar-abr \\
Psychotria suterella Müll.Arg. (Rubiaceae) & st & set-mai \\
Campomanesia xanthocarpa O.Berg (Myrtaceae) & st & nov-dez \\
Casearia decandra Jacq. (Flacourtiaceae) & st & jan-fev \\
Cinnamodendron dinisii Schwacke (Canellaceae) & st & dez- jan \\
\hline G.S:
\end{tabular}

G.S: grupo sucessional (pi; pioneira; si: secundária inicial; st: secundária tardia).

A definição de plântula foi estabelecida seguindo os critérios de Souza (2003), que compreende a fase entre a emissão da raiz primária e a formação da primeira folha ou eofilo. Visando a análise morfológica das plântulas, cerca de 500 sementes por espécie, de diferentes indivíduos, foram semeadas em bandejas plásticas, contendo vermiculita como substrato. As sementes permaneceram sob temperatura variando entre $22{ }^{\circ} \mathrm{C}$ a $26^{\circ} \mathrm{C}$, luminosidade de $347 \pm 55 \mu$ mol. $\mathrm{s}^{-1} . \mathrm{m}^{-2}$, com fotoperíodo de 12 horas (com e sem luz) e rega periódica a cada dois dias. Foram coletadas 10 plântulas de cada espécie e analisadas as características relacionadas aos cotilédones e eofilos como: a filotaxia, a forma, o tipo (simples ou composto), a margem, o tipo de venação, a presença ou ausência de tricomas e de estípulas. Para isso, foi utilizado a classificação de Hickey (1979). O desenvolvimento das plântulas, desde a protrusão da raiz até a emissão do primeiro par de eofilos foi acompanhado para todas as espécies. A observação e ilustração morfológica das plântulas foram realizadas com o auxílio de microscópio estereoscópico.

Para avaliar o grau de similaridade entre as espécies de grupos ecológicos distintos, foi realizada uma análise de agrupamento (Cluster analysis), com base em ausência (-) ou presença (+) de caracteres, utilizando-se o método Ward's como algoritmo. Os caracteres avaliados foram: tipo de dispersão, consistência dos frutos, apêndices epidérmicos ou excrescências na semente, tecido de reserva na semente e ocorrência de tricomas nas plântulas. Foram consideradas significativas as análises com índice cofenético superior a 0,7 . A análise de agrupamento foi realizada com o auxílio do programa Past, versão 1.34 (HAMMER et al., 2001).

\section{RESULTADOS} tabela 2 .

A caracterização morfológica dos frutos e sementes das 18 espécies avaliadas estão descritas na

Fruto

Em geral, o fruto das espécies pioneiras é do tipo cápsula lenhosa deiscente, e a unidade de dispersão é a semente. Apenas Moquiniastrum polymorphum tem fruto do tipo cipsela e Schinus terebinthifolius do tipo drupa indeiscente, com a unidade de dispersão constituída pelo endocarpo mais a semente. As sementes das espécies pioneiras têm dispersão anemocórica, exceto em $S$. terebinthifolius, que tem dispersão zoocórica. As sementes anemocóricas possuem alas e/ou papus. A maioria das espécies secundárias iniciais também tem frutos do tipo cápsula, com exceção de Psidium cattleianum (baga).

FLORESTA, Curitiba, PR, v. 45, n. 4, p. 819 - 832, out. / dez. 2015.

Gogosz, A. M. et al.

ISSN eletrônico 1982-4688 / ISSN impresso 0015-3826

DOI: $10.5380 /$ rf.v45i4.35017 
Quanto à deiscência, todos os frutos das espécies secundárias iniciais se abrem na maturidade, com exceção do fruto de $P$. cattleianum que é indeiscente. Os diásporos de todas as secundárias iniciais são constituídos apenas pela semente. Entretanto, os mecanismos de dispersão das espécies desse grupo são variáveis, uma vez que em Cedrela fissilis, Lafoensia pacari e Handroanthus albus a dispersão é anemocórica, enquanto que em Casearia sylvestris e $P$. cattleianum é zoocórica. Gymnanthes klotzschiana, por sua vez, tem dispersão primária autocórica (balistocórica) e secundária hidrocórica e zoocórica.

Nas espécies secundárias tardias, ao contrário das pioneiras, a maioria dos frutos é indeiscente, classificados como drupa ou baga. Apenas Casearia decandra possui fruto deiscente, classificado como cápsula loculicida. Nesse grupo, a unidade de dispersão pode ser constituída pelo pericarpo, endocarpo mais a semente (Allophylus edulis, Ilex paraguariensis, Psychotria suterella) ou apenas pela semente (Mollinedia clavigera, Campomanesia xanthocarpa, C. decandra e Cinnamodendron dinisii). Ao contrário das pioneiras, nas secundárias tardias, os diásporos têm dispersão zoocórica (Tabela 2).

Tabela 2. Caracteres morfológicos dos frutos e das sementes de espécies da Floresta com Araucária, no sul do Brasil.

Table 2. Morphological characters of fruits and seeds from species of Araucaria Forest, in southern Brazil.

\begin{tabular}{|c|c|c|c|c|c|c|c|c|c|c|}
\hline \multirow{2}{*}{ Espécie } & \multicolumn{2}{|c|}{ Diásporo } & \multicolumn{4}{|c|}{ Semente } & \multicolumn{2}{|c|}{ Embrião } & \multirow{2}{*}{ G.S } & \multirow{2}{*}{ Fig } \\
\hline & diasp & dis & tipo & forma & end & teg & exc & tipo & & \\
\hline C. scabra & sem & ane & cap & eli & inc & mem & ala-mar & esp & pi & $1 \mathrm{~A}$ \\
\hline M. polymorphum & fru & ane & cip & $\operatorname{lin}$ & inc & crt & pap & $\operatorname{lin}$ & pi & $1 \mathrm{~B}$ \\
\hline L. ternata & sem & ane & cap-sep & eli & inc & mem & ala-lat & esp & pi & $1 \mathrm{C}$ \\
\hline S. terebinthifolius & end-sem & zoo & dru & ren & inc & mem & aus & esp & pi & $1 \mathrm{D}$ \\
\hline L. divaricata & sem & ane & cap & eli & inc & crt & ala & esp & pi & $1 \mathrm{E}$ \\
\hline C. sylvestris & sem & zoo & cap-loc & eli & con & crt & ari-car & esp & si & $1 \mathrm{~F}$ \\
\hline C. fissilis & sem & ane & cap-sep & ovd & inc & crt & ala-lat & esp & si & $1 \mathrm{G}$ \\
\hline L. pacari & sem & ane & cap & obo & inc & crt & ala-mar & esp & si & $1 \mathrm{H}$ \\
\hline P. cattleianum & sem & zoo & bag & glo & inc & cor & ope & pim & si & $1 \mathrm{I}$ \\
\hline G. klotzschiana & sem & bal & cap-tri & eli & con & $\mathrm{crt}$ & crc & esp & si & $1 \mathrm{~J}$ \\
\hline H. albus & sem & ane & síl & eli & inc & mem & ala-lat & cor & si & $1 \mathrm{~K}$ \\
\hline A. edulis & end-sem & zoo & dru & ovó & inc & mem & aus & pli & st & $1 \mathrm{~L}$ \\
\hline I. paraguariensis & end-sem & zoo & dru & eli & con & mem & aus & glo & st & $1 \mathrm{M}$ \\
\hline M. clavigera & sem & zoo & dru & eli & con & crt & aus & esp & st & $1 \mathrm{~N}$ \\
\hline P. suterella & end-sem & zoo & dru & eli & con & mem & gld & esp & st & 10 \\
\hline C. xanthocarpa & sem & zoo & bag & eli & inc & crt & gld & pim & st & $1 \mathrm{P}$ \\
\hline C. decandra & sem & zoo & cap-loc & eli & con & crt & ari-car & esp & st & $1 \mathrm{Q}$ \\
\hline C. dinisii & sem & zoo & bag & ren & con & crt & aus & pan & st & $1 \mathrm{R}$ \\
\hline
\end{tabular}

diasp: diásporo (end: endocarpo, fru: fruto, sem: semente); dis: dispersão (ane: anemocoria, bal: balistocórica, zoo: zoocoria); tipo (bag: baga, cap: cápsula, cip: cipsela, dru: drupa, cap-loc: loculicida, cap-sep: septicida, sil: síliqua, cap-tri: tricoca); forma (eli: elipsóide, glo; globosa, lin: linear, obo: obovada, ovd: ovóide, ren: reniforme); end: endosperma (con: conspícuo, inc: inconspícuo); teg: tegumento (crt: cartáceo, cor: coriáceo, mem: membranáceo,); exc: excrescência (ala: ala, ari: arilo, aus: ausente, car: carnoso, crc: carúncula, gld: glândula, lat: lateral, mar: marginal, ope: opérculo, pap: papus); tipo (cor: cordiforme, esp: espatulado, glo: globoso, lin: linear, pan: pandurado, pim: pimentóide, pli: plicado); G.S: grupo sucessional (pi: pioneira, si: secundária inicial, st: secundária tardia).

\section{Semente}

As sementes da maioria das espécies pioneiras têm formato elipsóide, com tegumento membranáceo, exceto em $S$. terebinthifolius e $M$. polymorphum, cujas sementes são reniforme e linear, respectivamente, ambas com tegumento cartáceo. Nesse grupo, o tecido de reserva é ausente ou ocorre em pequena quantidade. Nas pioneiras, as sementes possuem apêndices epidérmicos que auxiliam no processo de dispersão (anemocórica). Dentre esses, destacam-se as alas (ou asas) e o papus piloso. Em geral, o embrião das espécies pioneiras é espatulado, com exceção de M. polymorphum, que tem embrião linear (Tabela 2 e Figura 1). 

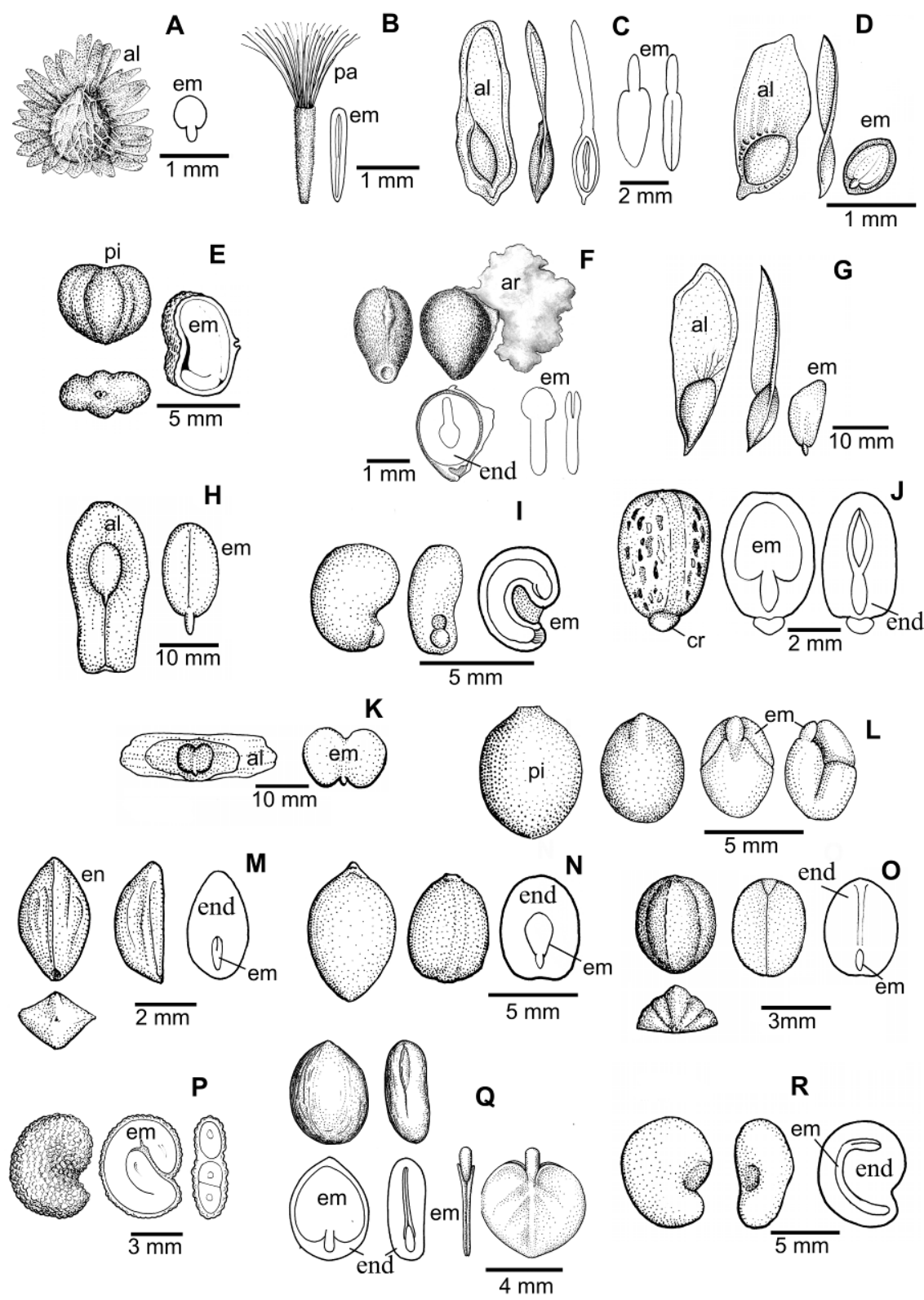

Figura 1. Morfologia das sementes de espécies de diferentes grupos ecológicos. A: C. scabra; B: M. polymorphum; C: L. ternata; D: L. divaricata; E: S. terebinthifolius; F: C. sylvestris; G: C. fissilis; H: L. pacari; I: P. cattleianum; J: G. klotzschiana; K: H. albus; L: A. edulis; M: I. paraguariensis; $\mathrm{N}$ : M. clavigera; O: P. suterella; P: C. xanthocarpa; Q: $C$. decandra; R: C. dinisii. (A - E: pioneiras; F - K: secundárias iniciais; L - R: secundárias tardias). (al: ala; ar: arilo; cr: carúncula; end: endosperma; em: embrião; pa: papus; pi: pirênio). Ilustrações: Cosmo e Gogosz.

Figure 1. Morphology of seeds of different ecological groups. A: C. scabra; B: M. polymorphum; C: $L$. ternata; D: L. divaricata; E: S. terebinthifolius; F: C. sylvestris; G: C. fissilis; H: L. pacari; I: P. cattleianum; J: G. klotzschiana; K: H. albus; L: A. edulis; M: I. paraguariensis; N: M. clavigera; O: P. suterella; P: C. xanthocarpa; Q: C. decandra; R: C. dinisii. (A - E: pioneer, F - K: early secondary, L - R: late secondary). (al: ala; ar: aryl; cr: carunche; end: endosperm, em: embryo; pa: papus; pi: pyrene). Illustrations: Cosmo and Gogosz.

FLORESTA, Curitiba, PR, v. 45, n. 4, p. 819 - 832, out. / dez. 2015.

Gogosz, A. M. et al.

ISSN eletrônico 1982-4688 / ISSN impresso 0015-3826

DOI: $10.5380 /$ rf.v45i4.35017 
No grupo das espécies secundárias iniciais, as sementes variam entre elipsóides, ovóides, globosas e obovadas. Os tegumentos podem ser membranáceos, cartáceos ou coriáceos. Nesse grupo, o tecido de reserva é inconspícuo, exceto em C. sylvestris e G. klotzschiana. As secundárias iniciais possuem diversos tipos de excrescências, como arilo carnoso, carúncula e alas, que auxiliam na dispersão, pelo vento ou por animais. Neste grupo, predomina o embrião espatulado, com exceção de $P$. cattleianum, que é pimentóide, e H. albus, que é cordiforme (Tabela 2 e Figura 1).

Nas espécies secundárias tardias, a semente é elipsóide, exceto em A. edulis, que possui semente ovóide, e em $C$. dinisii, que tem semente reniforme. Ao contrário do que se observa nas espécies pioneiras, na maioria das secundárias tardias, o tecido de reserva é conspícuo, com exceção de A. edulis e C. xanthocarpa, que possuem sementes exalbuminosas. Ainda nesse grupo, ocorrem tegumentos da semente com consistência membranácea ou cartácea. Em $C$. decandra, espécie secundária tardia, ocorre excrescência, que auxilia na dispersão zoocórica, como arilo. $\mathrm{O}$ embrião pode ser do tipo plicado, globoso, espatulado, pimentóide ou pandurado (Tabela 2 e Figura 1).

\section{Plântula}

As plântulas de todos os grupos ecológicos estudados são fanerocotiledonares, com desenvolvimento epígeo e cotilédones foliáceos. As características morfológicas das plântulas podem ser observadas nas figuras 2, 3 e 4 . A maioria das espécies pioneiras tem tricomas nos eofilos, enquanto que tal característica não está presente nas secundárias tardias. Dentre as espécies secundárias iniciais, apenas Luehea divaricata e $H$. albus possuem tricomas nos eofilos. As espécies pioneiras têm cotilédones finos (membranáceos), contrastando com as secundárias tardias, nas quais esses tendem a ser mais espessos, especialmente em A. edulis. Nesta espécie, embora os cotilédones sejam fotossintetizantes, também exercem a função de reserva.

Na maioria das espécies secundárias tardias observou-se que os cotilédones permanecem por um período mais longo presos no interior da semente após a germinação, exercendo a função haustorial. Com relação ao tamanho das plântulas, as espécies pioneiras tendem a ser menores do que as espécies secundárias tardias, enquanto que nas secundárias iniciais ocorrem plântulas de tamanho variável (Figuras 2,3 e 4). As plântulas das espécies pioneiras têm um desenvolvimento mais rápido, em relação às plântulas das espécies secundárias tardias.

Nota-se que nas espécies pioneiras predominam eofilos com forma elíptica, filotaxia alterna, limbo simples e margem serreada. Já nas secundárias tardias, a forma dos eofilos é bastante variável, a filotaxia é alterna ou oposta, o limbo é simples ou composto e a margem inteira ou serrada. Nas secundárias iniciais, por sua vez, predominam eofilos com forma elíptica ou lanceolada, filotaxia oposta, limbo simples ou composto e margem inteira ou serreada. Com relação à venação dos cotilédones e eofilos, nota-se que predomina o tipo pinada camptódroma na maioria das espécies estudadas, com poucas exceções dentro dos grupos ( $L$. divaricata, do tipo actinódromo suprabasal e $M$. clavigera, com veneção dos cotilédines do tipo actinódroma basal e dos eofilos o tipo pinada camptódroma).

\section{Agrupamento das espécies}

Considerando a análise de agrupamento, com base nos principais caracteres qualitativos, observou-se a formação de dois grupos distintos (Figura 5). O primeiro é composto pelas espécies pioneiras, exceto $S$. terebinthifolius, e por algumas espécies secundárias iniciais $(H$. albus, L. pacari e $C$. sylvestris). O segundo grupo, por sua vez, é formado pelas espécies secundárias tardias e algumas secundárias iniciais ( $P$. cattleianum, $C$. fissilis e G. klotzschiana).

\section{DISCUSSÃO}

As características morfológicas observadas neste estudo refletem distintas estratégias de dispersão e estabelecimento dos diferentes grupos de espécies analisados. Segundo Ressel et al. (2004), fatores como o tipo de dispersão, tamanho das sementes e até mesmo o sistema sexual estão associados à morfologia funcional mais adaptada a cada estágio sucessional. Nas espécies pioneiras, o predomínio de frutos secos, sementes pequenas, com apêndices, como alas e tricomas, representa um conjunto de mecanismos que facilitam a dispersão pelo vento (BARROSO et al., 1999). Nas primeiras fases da sucessão, as florestas geralmente são dominadas por espécies de sementes pequenas (WESTOBY et al., 2002). Essas características são comuns nas espécies que ocorrem em ambientes abertos e em estágios iniciais de sucessão (PIÑA-RODRIGUES et al., 1990). Além disso, os frutos secos e as sementes disseminadas pelo vento geralmente são dispersos a grandes distâncias, em relação à planta mãe (KHURANA et al., 2006), o que representa uma vantagem para a sua colonização em outras áreas. 
A

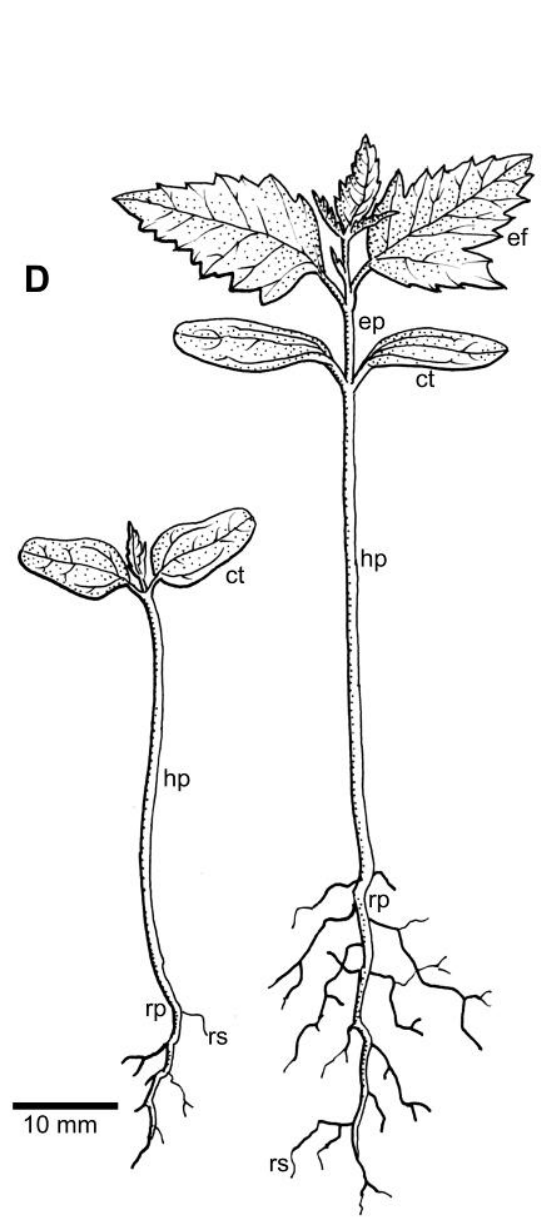

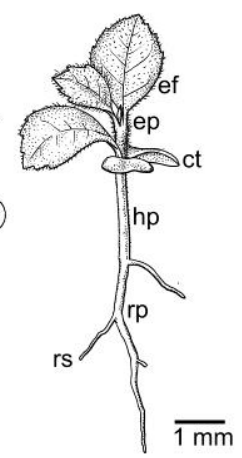

\section{(1)}

B

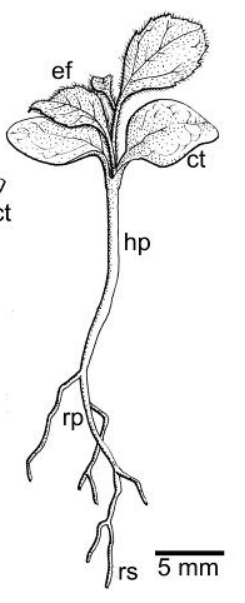

C
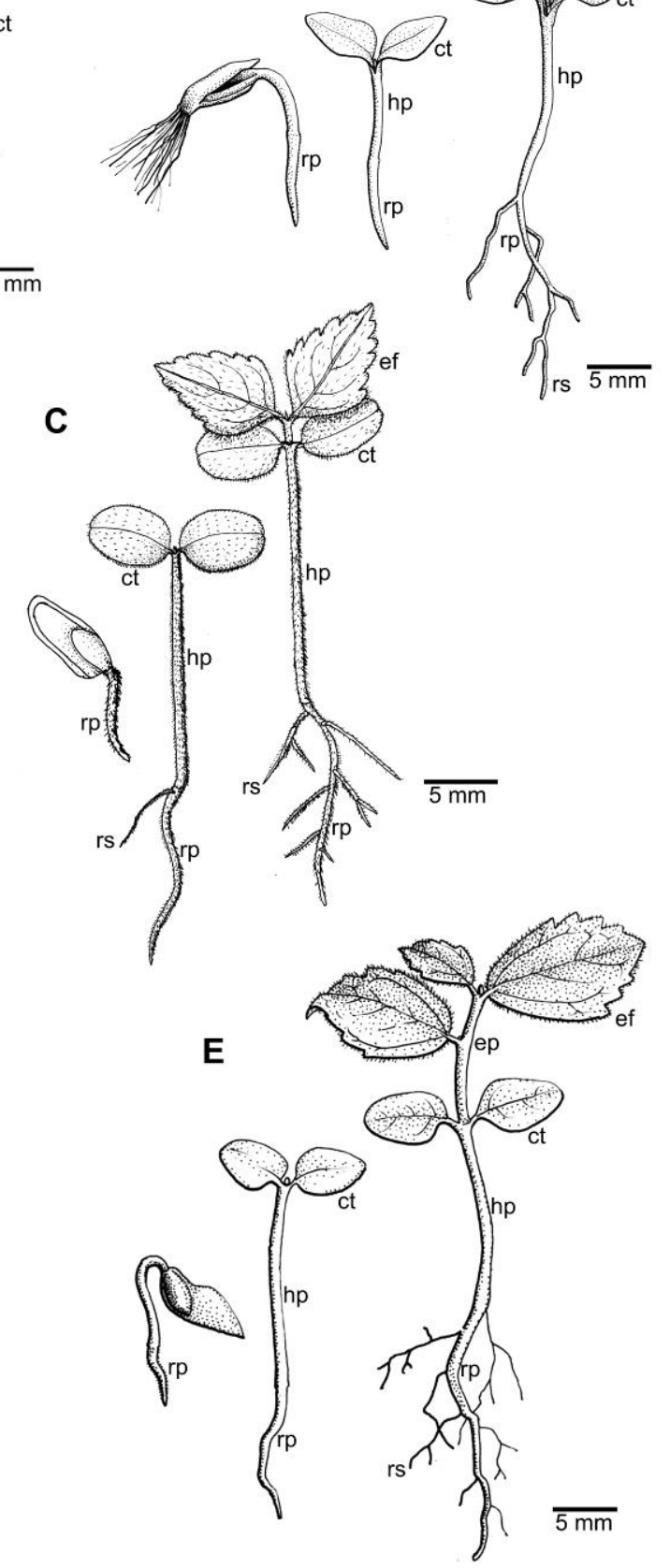

Figura 2. Fases de desenvolvimento das plântulas de espécies pioneiras. A: C. scabra; B: M. polymorphum; C: L. ternata; D: S. terebinthifolius; E: L. divaricata. ct: cotilédone; ef: eofilo; ep: epicótilo; hp: hipocótilo; rp: raiz primária; rs: raiz secundária. Ilustrações: Cosmo e Gogosz.

Figure 2. Stages of development of seedlings of pioneer species. A: C. scabra; B: M. polymorphum; C: L. ternata; D: S. terebinthifolius; E: L. divaricata. ct: cotyledon; ef: eophyll; ep: epicotyl; hp: hypocotyl; rp: primary root; rs: secondary root. Illustrations: Cosmo and Gogosz.

FLORESTA, Curitiba, PR, v. 45, n. 4, p. 819 - 832, out. / dez. 2015.

Gogosz, A. M. et al.

ISSN eletrônico 1982-4688 / ISSN impresso 0015-3826 

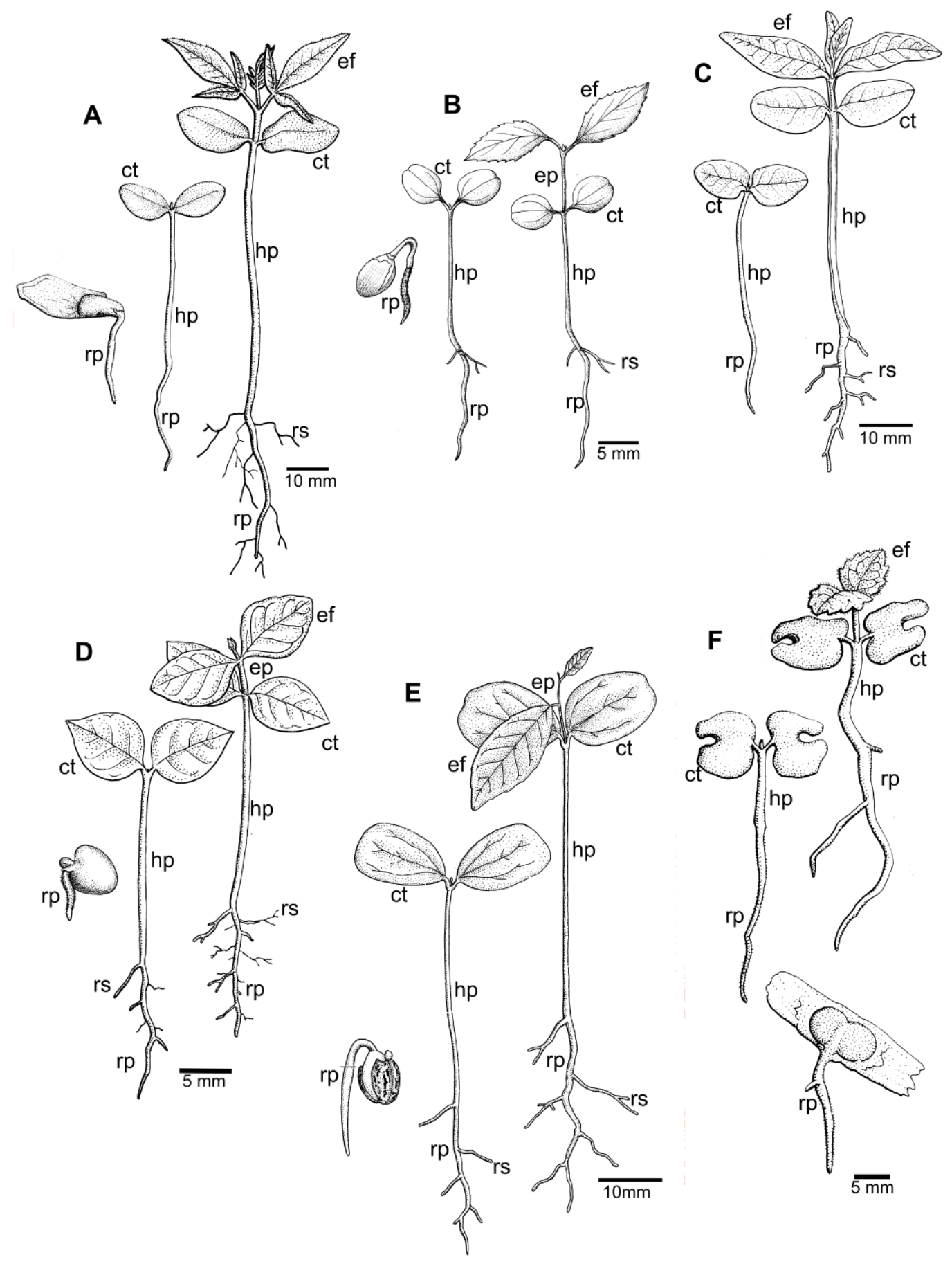

Figura 3. Fases de desenvolvimento das plântulas de espécies secundárias iniciais. A: $C$. fissilis; B: $C$. sylvestris; C: L. pacari; D: P. cattleianum; E: G. klotzschiana; F: H. albus. ct: cotilédone; ef: eofilo; ep: epicótilo; hp: hipocótilo; rp: raiz primária; rs: raiz secundária. Ilustrações: Cosmo e Gogosz.

Figure 3. Stages of seedling development of early secondary species. A: C. sylvestris; B: C. fissilis; C: $L$. pacari; D: P. cattleianum; E: G. klotzschiana; F: H. albus. ct: cotyledon; ef: eophyll; ep: epicotyl; hp: hypocotyl; rp: primary root; rs: secondary root. Illustrations: Cosmo and Gogosz. 


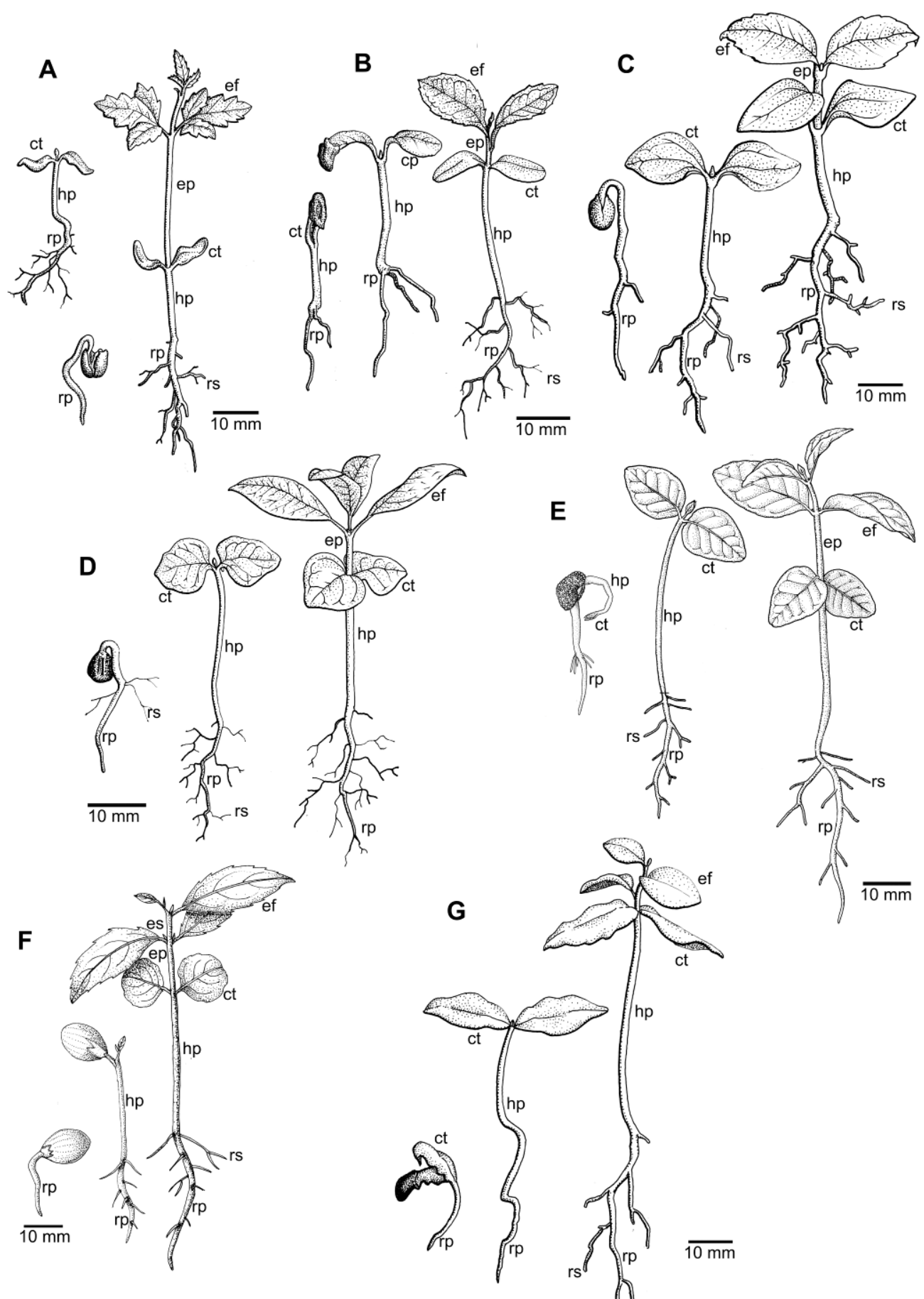

Figura 4. Fases de desenvolvimento das plântulas de espécies secundárias tardias. A: A. edulis; B: I. paraguariensis; C: M. clavigera; D: P. suterella; E: C. xanthocarpa; F: C. decandra; G: $C$. dinisii. ct: cotilédone; ef: eofilo; ep: epicótilo; es: estípula; hp: hipocótilo; rp: raiz primária; rs; raiz secundária. Ilustrações: Cosmo e Gogosz.

Figure 4. Stages of seedling development of late secondary species. A: A. edulis; B: I. paraguariensis; C: M. clavigera; D: P. suterella; E: C. xanthocarpa; F: C. decandra; G: C. dinisii. ct: cotyledon; ef: eophyll; ep: epicotyl; es: stipule, hp: hypocotyl; rp: primary root; rs, secondary root. Illustrations: Cosmo and Gogosz.

FLORESTA, Curitiba, PR, v. 45, n. 4, p. 819 - 832, out. / dez. 2015 


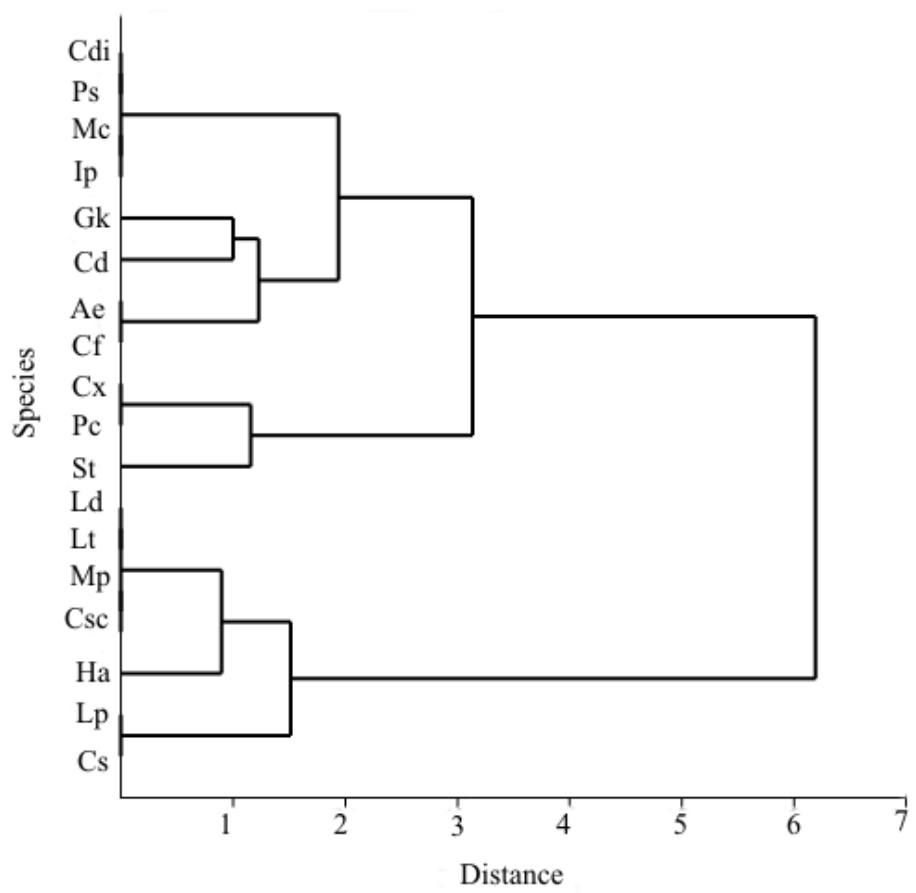

Figura 5. Análise de agrupamento, com base em ausência e presença de caracteres morfológicos dos frutos, das sementes e das plântulas. (Csc: C. scabra; Mp: M. polymorphum; Lt: L. ternata; Ld: $L$. divaricata; St: S. terebinthifolius; Cs: C. sylvestris; Cf: C. fissilis; Lp: L. pacari; Pc: P. cattleianum; Gk: G. klotzschiana Sc: S. commersoniana; Ha: H. albus; Ae: A. edulis; Ip: I. paraguariensis; Mc: M. clavigera; Ps: P. suterella; $\mathrm{Cx}$ : C. xanthocarpa; Cd: C. decandra; Cdi: C. dinisii).

Figure 5. Cluster analysis, based on the absence and presence of morphological characters of fruits, seeds and seedlings. (Csc: C. scabra; Mp: M. polymorphum; Lt: L. ternata; Ld: L. divaricata; St: S. terebinthifolius; Cs: C. sylvestris; Cf: C. fissilis; Lp: L. pacari; Pc: P. cattleianum; Gk: $G$. klotzschiana Sc: S. commersoniana; Ha: H. albus; Ae: A. edulis; Ip: I. paraguariensis; Mc: M. clavigera; Ps: P. suterella; Cx: C. xanthocarpa; Cd: C. decandra; Cdi: C. dinisii).

Além do menor tamanho das sementes das espécies pioneiras, estas tendem a produzir sementes em grande quantidade por fruto, como, por exemplo, Clethra scabra, Moquiniastrum polymorphum, Lamanonia ternata e Luehea divaricata. Estes resultados corroboram outros estudos em ecossistemas florestais (LEISHMAN, 2001; KHURANA et al., 2006).

Em contraste, nas espécies secundárias tardias prevaleceram os frutos carnosos e sementes maiores, com algum tipo de atrativo para seus dispersores (zoocoria), como, por exemplo, arilo carnoso. Plantas com dispersão zoocórica possuem frutos e/ou sementes com diversas características morfológicas e organolépticas que estimulam e facilitam o seu consumo por animais e, potencialmente, a dispersão de suas sementes (BARROSO et al., 1999). De acordo com Paoli (2006), embora sementes grandes possam ter dispersão mais restrita e um menor número de dispersores zoocóricos, resultam em maior sucesso no estabelecimento, refletindo na sobrevivência das plântulas. O maior tamanho da semente pode contribuir para o estabelecimento das plântulas na sombra (JURADO; WESTOBY, 1992), uma vez que sementes maiores podem produzir plântulas com maior vigor (MOLOFSKY; AUGSPURGER, 1992), devido à maior quantidade de recursos que podem permanecer armazenados, para serem utilizados ao longo do desenvolvimento da plântula (GARWOOD, 1996).

A ausência de endosperma na semente das espécies pioneiras estudadas está relacionada com o ambiente em que estas se estabelecem e com a forma de dispersão, uma vez que tendem a ter um rápido desenvolvimento inicial, mais dependente da fotossíntese e menos dependente de reservas da semente. 
Por outro lado, a maioria das espécies secundárias tardias se estabelece em ambientes com pouca intensidade luminosa, sendo mais dependente das reservas contidas nas sementes ou nos cotilédones (GARWOOD, 1996). Além disso, as plântulas desse grupo têm um desenvolvimento mais lento, os cotilédones tendem a ser mais espessos e permanecem por maior período no interior da semente. De acordo com Kitajima e Myers (2008), espécies com sementes maiores têm grande quantidade de carboidratos estocados no cotilédone ou na semente. Isso pode ser uma vantagem para sobrevivência das plântulas na sombra, uma vez que estas podem manter-se por um período relativamente longo à custa das reservas dos cotilédones, até que as primeiras folhas possam se desenvolver (BARALOTO; FORGET, 2007). Embora as plântulas sejam normalmente divididas em grupos mais ou menos distintos, quanto à função do cotilédone, é possível que um mesmo cotilédone exerça mais de uma função no desenvolvimento da plântula.

Outra característica que merece destaque é o tipo de desenvolvimento dos cotilédones. A maioria das espécies estudadas expõe seus cotilédones acima do solo, sendo classificadas como epígeas. No entanto, Ilex paraguariensis (secundária tardia) tem germinação fanerocotiledonar, epígea, com uma fase hipógea, em que a semente permanece no solo até sua elevação epigeal (KUNIYOSHI, 1981). Apesar da maioria dos estudos relacionarem plântulas fanerocotiledonares, epigeas e cotilédones foliáceos, com espécies pioneiras e, plântulas criptocotiledonares, hipógea e cotilédones de reserva, com as secundárias tardias (IBARRA-MANRÌQUEZ et al., 2001; RESSEL et al., 2004), no presente estudo observa-se que a maioria das espécies secundárias tardias também se enquadram no primeiro tipo morfofuncional. Destacase ainda que, I. paraguariensis, Allophylus edulis, Casearia decandra (secundárias tardias) e Gymnanthes klotzschiana (secundária inicial) permanecem com os cotilédones no interior da semente por tempo mais prolongado, durante o desenvolvimento da plântula, provavelmente exercendo função haustorial, antes de se tornarem funcionalmente fotossintetizantes. Além disso, A. edulis tem cotilédones fotossintetizantes, porém também com função de reserva, considerando suas características morfo-anatômicas (presença de cloroplastos e amido em grande quantidade) (GOGOSZ, 2013).

As características observadas nas espécies pioneiras, como sementes pequenas, leves e plântulas fanerocotiledonares, epigeas, com cotilédones foliáceos propiciam vantagens competitivas em ambientes com alta intensidade de luz, uma vez que os cotilédones rapidamente se elevam e se abrem, sustentando o desenvolvimento inicial da plântula a partir da fotossíntese (RESSEL et al., 2004).

A presença de tricomas nas plântulas das espécies pioneiras pode estar relacionada com o ambiente em que estas se estabelecem. Nos ambientes com alta irradiação, os tricomas podem ter função de reduzir a evapotranspiração (WRIGHT et al., 2000) e a radiação diretamente incidida sobre as folhas (SMITH et al., 1997), além de poderem funcionar como uma barreira mecânica contra o ataque de insetos herbívoros (THEOBALD et al., 1979).

A predominância dos caracteres morfológicos observados nos eofilos das espécies pioneiras corrobora o estudo de Schneider et al. (2003). Segundo estes autores, folhas pequenas, simples, com forma elíptica e margem serreada são comuns em espécies de ambientes abertos, como aquelas que ocorrem na fase inicial da sucessão. Entretanto, há poucas informações na literatura sobre a relevância adaptativa dessas características, especialmente em plântulas. Com relação à ocorrência de limbo composto nos eofilos de algumas espécies estudadas, não há um padrão geral para esta característica entre os grupos. De acordo com Givinish (1976), em florestas tropicais e subtropicais, folhas compostas tendem a ser frequentes em algumas famílias, como por exemplo, Bignoniaceae, Anacardiaceae, Cunoniaceae e Sapindaceae. Dentre as espécies estudadas com folhas compostas, pertencentes a estas famílias, destacam-se: Handroanthus albus, Schinus terebinthifolius, L. speciosa e A. edulis, respectivamente. Portanto, tal característica tem provavelmente maior correspondência filogenética do que ecológica.

\section{CONCLUSÕES}

- As características morfológicas avaliadas estão relacionadas aos grupos sucessionais estudados.

- As espécies pioneiras e as secundárias tardias têm características morfológicas nitidamente distintas, relacionadas às suas estratégias específicas de dispersão, germinação e estabelecimento. As secundárias iniciais, por sua vez, não formam um grupo homogêneo, tendo algumas espécies com características semelhantes às pioneiras e outras mais próximas às espécies secundárias tardias.

FLORESTA, Curitiba, PR, v. 45, n. 4, p. 819 - 832, out. / dez. 2015.

Gogosz, A. M. et al.

ISSN eletrônico 1982-4688 / ISSN impresso 0015-3826 


\section{REFERÊNCIAS}

BARALOTO, C.; FORGET, P. M. Seed size, seedling morphology, and response to deep shade and damage in neotropical rain forest trees. American Journal of Botany, v. 94, n. 6, p. 901 - 911, 2007.

BARROSO, G. M.; MORIM, M. P.; PEIXOTO, A. L.; ICHASO, C. L. F. Frutos e sementes: morfologia aplicada à sistemática de dicotiledôneas. Viçosa: UFV, 1999. 443 p.

COSMO, N. L.; GOGOSZ, A. M.; NOGUEIRA, A. C.; BONA, C.; KUNIYOSHI, Y. S. Morfologia do fruto, da semente e morfo-anatômia da plântula de Vitex megapotamica (Spreng.) Moldenke (Lamiaceae). Acta Botânica Brasílica, v. 23, n. 2, p. 389 - 397, 2009.

COSMO, N. L.; NOGUEIRA, A. C.; LIMA, J. G. L.; KUNIYOSHI, Y. S. Morfologia de fruto, semente e plântula de Sebastiania commersoniana, Euphorbiaceae. Floresta, v. 40, n. 2, p. 419 - 428, 2010.

GARWOOD, M. D. Functional morphology of tropical tree seedlings. In: SWAINE, M. D. Ecology of tropical forest tree seedlings. Paris: Unesco/ Parthenon, 1996. p. 59 - 119.

GIVINISH, T. J. On the adaptive significance of compound leaves, with particular reference to tropical trees. In: TOMLINSON, P. B; ZIMMERMANN, M. H. Tropical trees as living systems. London: Cambridge University Press, 1976, p. 351 - 380.

GOGOSZ, A. M.; COSMO, N. L.; BONA, C.; SOUZA, L. A. de. Morfo-anatômia da plântula de Campomanesia xanthocarpa O. Berg. (Myrtaceae). Acta Botanica Brasílica, v. 24, n. 3, p. 613 - 623, 2010.

GOGOSZ, A. M. Morfologia funcional de plântulas como indicador fisionômico da dinâmica de regeneração de espécies arbóreas da Floresta Ombrófila Mista, Paraná. 93 f. Tese (Doutorado em Ecologia e Conservação) - Universidade Federal do Paraná, Curitiba, 2013.

HAMMER, Ø.; HARPER, D. A. T.; RYAN, P. D. 2001. PAST: Paleontological statistics software package for education and data analysis. Paleontologia Eletrônica, v. 4, n. 1. Disponível em: <http://palaeo-eletronica.org/2001_1/past/issue1_01.htm>. Acesso em: 01/03/2012.

HICKEY, L. J. A revised classification of the architecture of dicotyledonous leaves. In: METCALF, C. R.; CHALK, L. Anatomy of the dicotyledons. Oxford: Oxford University Press, 1979. p. 24 - 39.

IBARRA-MANRÍQUEZ, G.; RAMOS, M. M.; OYAMA, K. Seedling functional types in a lowland rain forest in Mexico. American Journal of Botany, v. 88, p. 1801 - 1812, 2001.

JURADO, E.; WESTOBY, M. Seedling growth in relation to seed size among species of arid Australia. Journal of Ecology, v. 80, p. 407 - 416, 1992.

KHURANA, E.; SAGAR, R.; SINGH, J. S. Seed size: a key trait determining species distribution and diversity of dry tropical forest in northern India. Acta Oecologica, v. 26, p. 196 - 204, 2006.

KITAJIMA, K. Seed and seedling ecology. In: PUGNAIRE, F. I.; VALLADARES, F. Functional plant ecology. New York: CRC Press, 2007. p. 549 - 566.

KITAJIMA, K.; MYERS, J. A. Seedling ecophysiology: strategies toward achievement of positive net carbon balance. In: LECK, M. A.; PARKER, V. T.; SIMPSON, R. L. Seedling ecology and evolution. New York: Cambridge University Press, 2008. p. 172 - 188.

KUNIYOSHI, Y. S. Morfologia da semente e da germinação de 25 espécies arbóreas de uma Floresta com Araucária. 233 f. Dissertação (Mestrado em Ciências Florestais) - Universidade Federal do Paraná, Curitiba, 1981.

LECK, M. A.; SIMPSON, R. L.; PARKER, V. T. Why seedling? In: LECK, M. A.; PARKER, V. T.; SIMPSON, R. L. Seedling ecology and evolution. New York: Cambridge University Press, 2008. p. 3 - 13.

LEISHMAN, M. R. Does the seed size/number trade-off model determine plant community structure? An assessment of the model mechanisms and their generality. Oikos, v. 93, p. 294 - 302, 2001. 
FLORA DO BRASIL. Lista de Espécies da Flora do Brasil. Jardim Botânico do Rio de Janeiro. Disponível em: <http://floradobrasil.jbrj.gov.br/>. Acesso em: 09/12/2014.

MAACK, R. Geografia física do Estado do Paraná. Rio de Janeiro: J. Olympio, 1981. 350 p.

MOLES, A. T.; ACKERLY, D. D.; WEBB, C. O.; TWEDDLE, J. C.; DICKIE, J. B.; WESTOBY, M. A. Brief History of Seed Size. Science, v. 307, p. 579 - 580, 2005.

MOLES, A. T.; LEISHMAN, M. R. The seedling as part of a plant's life history strategy. In: LECK, M. A.; PARKER, V. T.; SIMPSON, R. L. Seedling ecology and evolution. New York: Cambridge University Press, 2008. p. 217 - 237.

MOLOFSKY, J.; AUGSPURGER, C. K. The effect of leaf litter on early seedling establishment in a tropical forest. Ecology, v. 73, p. 68 - 77, 1992.

PAOLI, A. A. S. Semente. In: SOUZA, L. A. Anatomia do fruto e da semente. Ponta Grossa: Editora UEPG, 2006. p. 127 - 163.

PIÑA-RODRIGUES, F. C. M.; COSTA, L. G. S.; REIS, A. Estratégias de estabelecimento de espécies arbóreas e o manejo de florestas tropicais. In: Congresso Florestal Brasileiro, 6, 1990, Campos do Jordão. Anais do VI Congresso Florestal Brasileiro, São Paulo: SSB/SBEF, 1990. v. 3, p. 676 - 684.

REGO, S. S.; COSMO, N. L.; GOGOSZ, A. M.; KUNIYOSHI, Y. S.; NOGUEIRA, A. C. Caracterização morfológica e germinação de sementes de Curitiba prismatica (D. Legrand) Salywon \& Landrum. Revista Brasileira de Sementes, v. 33, n. 4, p. 616 - 625, 2011.

RESSEL, K.; GUILHERME, F. A. G.; SCHIAVINI, I.; OLIVEIRA, P. E. Ecologia morfofuncional de plântulas de espécies arbóreas da Estação Ecológica do Panga, Uberlândia, Minas Gerais. Revista Brasileira de Botânica, v. 27, p. 311 - 323, 2004.

SCHNEIDER, J. V.; ZIPP, D.; GAVIRIA, J.; ZIZKA, G. Successional and mature stands in an upper Andean rain forest transect of Venezuela: do leaf characteristics of wood species differ? Journal of Tropical Ecology, v. 19, p. 251 - 259, 2003.

SMITH, W. K.; VOGELMANN, T. C.; DELUCIA, E. H.; BELL, D. T.; SHEPHERD, K. A. Leaf Form and Photosynthesis. Bio Science, v. 47, p. 785 - 793, 1997.

SOUZA, L. A. Morfologia e anatomia vegetal: célula, tecidos, órgãos e plântula. Ponta Grossa: Editora UEPG, 2003, 258 p.

THEOBALD, W. L.; KRAHULIK, J. L.; ROLLINS, R. C. Trichome description and classification. In: METCALFE, C. R.; CHALK, L. Anatomy of the dicotyledons. Oxford, Clarendon Press, p. 40 - 53, 1979.

WESTOBY, M.; FALSTER, D. S.; MOLES, A. T.; VESK, P. A.; WRIGHT, I. J. Plant ecological strategies: some leading dimensions of variation between species. Annual Review of Ecology and Systematics, v. 33, p. 125 - 159, 2002.

WRIGHT, I. J.; CLIFFORD, H. T.; KIDSON, R.; REED, M. L.; RICE, B. L.; WESTOBY, M. A survey of seed and seedling characters in 1744 Australian dicotyledon species: cross-species trait correlations and correlated trait-shifts within evolutionary lineages. Biological Journal of the Linnean. Society, v. 69 , p. $521-547,2000$. 
FLORESTA, Curitiba, PR, v. 45, n. 4, p. 819 - 832, out. / dez. 2015. Gogosz, A. M. et al. 